\title{
Electrochemical Oxidation of Sulphite in Neutral Media on Platinum Anode
}

\author{
Andreea-Floriana Enache, Mircea Laurentiu Dan, Nicolae Vaszilcsin * \\ University Politehnica Timisoara, Faculty of Industrial Chemistry and Environmental Engineering, \\ 300223, Parvan 6, Timisoara, Romania \\ *E-mail: nicolae.vaszilcsin@upt.ro
}

doi: $10.20964 / 2018.05 .07$

Received: 9 January 2018 / Accepted: 26 February 2018 / Published: 10 April 2018

In this paper, electrochemical behavior of sulphite ions on platinum in neutral solution $\left(1 \mathrm{~mol} \mathrm{~L}^{-1}\right.$ $\mathrm{Na}_{2} \mathrm{SO}_{4}$ ) has been studied in order to identify the relationship between the sulphite concentration in the electrolyte solution $\left(10^{-3}, 10^{-2}, 10^{-1}, 5 \cdot 10^{-1}\right.$ and $\left.1 \mathrm{~mol} \mathrm{~L}^{-1}\right)$ and kinetic parameters of the anodic process. Electrochemical behavior of sulphite in the test solutions has been studied by linear and cyclic voltammetry. More information regarding the studied process occurring at electrode/electrolyte interface and kinetic parameters (current density $i_{\mathrm{o}}$ and anodic transfer coefficient $\alpha$ ) were obtained by Tafel plots method. Further, electrochemical impedance spectroscopy was carried out to confirm obtained data on platinum electrode. As well, chrono-electrochemical methods (chronoamperometry, chrono-potentiometry, chronocoulometry) were chosen in order to achieve the optimum parameters (current density, oxidation potential characteristic for sulphite electrooxidation and transformation degree of $\mathrm{SO}_{3}{ }^{2-}$ in the test solution).

Keywords: sulphite anodic oxidation, Tafel plots method, electrochemical impedance spectroscopy, chrono-electrochemical methods

\section{$\underline{\text { FULL TEXT }}$}

(C) 2018 The Authors. Published by ESG (www.electrochemsci.org). This article is an open access article distributed under the terms and conditions of the Creative Commons Attribution license (http://creativecommons.org/licenses/by/4.0/). 